\title{
Harnessing Digital Services for Co-creating Sustainability Value in the Retail Servicescape
}

\author{
Juuli Lumivalo \\ Faculty of IT \\ University of Jyväskylä \\ juuli.k.lumivalo@jyu.fi
}

\author{
Kati Clements \\ Faculty of IT \\ University of Jyväskylä \\ kati.clements@jyu.fi
}

\author{
Emma-Stiina Hannuksela \\ Faculty of IT \\ University of Jyväskylä \\ emma-stiina.l.valli@jyu.fi
}

\begin{abstract}
While the importance of sustainable consumption is well acknowledged and consumers increasingly demand sustainable alternatives, the consumption of environmentally strenuous products continues to grow. Technological solutions have been discussed for addressing the misalignment between consumers' attitudes and behavior. This study is the first to use the service-dominant logic lens to investigate how digital services may be harnessed to drive the co-creation of sustainability value in the retail industry. We conduct 10 semi-structured interviews with a Finnish retail company and its customers and reflect on the customers' experiences with respect to the company's value propositions in the servicescape. Our findings indicate that understanding and harnessing consumers' personal sustainability goals may be the key to designing digital services that help mitigate the impacts of consumption through value co-creation (VCC). We propose a preliminary framework for sustainability $V C C$ and value co-destruction (VCD) in the retail industry and discuss its implications.
\end{abstract}

\section{Introduction}

According to United Nations' principles of sustainable production and consumption, the use of services and products should expend fewer resources, "respond to basic needs and bring a better quality of life" [1]. The concept of sustainability refers not only to the environmental aspect of preserving natural resources [e.g., 2] but also to economic and socially ethical attributes, such as fair trade and labor [3, 4]. While emerging technological advancements show great potential in transitioning societies toward lower impact, it has been established that technology alone may not suffice in addressing issues such as climate change and related global humanitarian crises [5]. In fact, private consumption contributes substantially to environmental degradation, resource depletion, and social problems [e.g., 5-7]. Thus, consumers are increasingly aware of the critical role of their choices and how these may affect the way firms operate $[8,9]$. It follows, that businesses face an urgent need to evolve, in which digitalization may be harnessed for the co-creation of sustainability value (e.g., improving environmental well-being by reducing emissions and waste) $[10,11]$.

However, consumers struggle to adopt more sustainable consumption behaviors, and paradoxically, the global consumption of environmentally strenuous products continues to increase [e.g., 12-14]. Prevailing behavioral patterns and habits may be one of the underlying reasons preventing consumers from transitioning toward sustainable consumption aligned with their personal values [15]. Advocates have suggested divergent types of digital intervention techniques and applications, such as carbon footprint calculators, to help consumers transition toward sustainable lifestyles [e.g., 16-19]. We conceptualize the use of such solutions with the lens of the servicedominant logic (SDL) [20, 21], as service exchange, where resource inputs from the user (e.g., personal data and effort), are integrated with the value propositions and resources made available by the provider to cocreate sustainability value. However, negative value outcomes may also emerge (i.e., value co-destruction [VCD]), resulting in decreased negative outcomes, such as dissatisfaction and withdrawal $[22,23]$. Accordingly, the values proposed by retailers may not always be positively perceived by consumers.

As the success of digital services depends on their value creation potential for individual users and other involved stakeholders, service providers need to understand how value may emerge for their customers $[24,25]$. Given the rapid increase in consumers' awareness, firms must now learn to better understand their customers and foster value co-creation (VCC) with them [26]. However, research to date has not addressed the potential of digital services to support sustainabilityrelated VCC in the retail context. Beginning to address this need, we conduct a qualitative case study [27] 
investigating how a leading Finnish retail company cocreates or co-destroys value with its customers using digital services. We perform 10 in-depth interviews with representatives of the case company and its customers, addressing the following research question: How can retail companies harness digital services in co-creating sustainability with customers? Using the lens of SDL, we dissect the case company's sustainability-related value propositions and how customers respond to them through digital service exchange in the servicescape (i.e., during the shopping process). Our analysis outlines sustainability value propositions from the case company perspective, and links these with customers' experiences of positive and negative service use and their desires. We propose a preliminary framework as a first step for attaining an in-depth understanding of sustainability VCC and VCD through digital service use in the retail context.

\section{Theoretical background}

\subsection{Value propositions for supporting customers' sustainability goals}

Currently, one of emerging macrotrends in the retail industry is sustainability, meaning that "consumers expect retailers to run more sustainable businesses and reduce their impact on the environment [14.]" It follows, that firms must evolve in the way they propose value to customers and learn to assess understand customer value, a concept that can be regarded as a customer's perceived preference of the use of a product/service with respect to achieving the customer's personal goals for the use. To differentiate and succeed with the competition, companies must develop relevant and customer-oriented value propositions (i.e., a representation of how value can be created by a company's offerings) [25].

It is established that customers' perceptions of value strongly reflect their choices and consumption behavior [28]. Given consumers' increasing awareness of social, environmental and economic challenges, it can be inferred that ethical and responsible end goals increasingly drive consumer behavior. However, sustainability-related value propositions such as "locally sourced produce" may impact each consumer differently depending on different aspects such as personal goals and context. As a contextual and fluid concept, customer value can be encapsulated only through the understanding of and engagement with the targeted customers [29, 30].

Different technologies have been suggested as a means to develop value propositions for supporting consumers in their personal goals toward sustainable consumption patterns [e.g., 16, 31-33]. One of the most transformational developments brought onto companies by digitalization has been the skyrocketing amount of customer data available [34]. In particular, omnichannel retailers may derive substantial amounts of data regarding the customers' actions across channels, and induce customers' shopping goals, accordingly [35]. Thus, digitalization allows retailers with new ways of understanding the customer and proposing value. Retailers can develop personalized sustainabilityrelated value propositions, for instance by committing personal post-purchase shopping data or its calculated environmental impact to customers [31], or offering goal-driven promotions basing for instance on customers' online browsing data [35].

\subsection{Harnessing technology for facilitating sustainable behavioral change}

Aside from acting based on their desired goals and values, customers may be rooted in particular behavioral patterns, contributing to an emerging misalignment between customers' attitudes and behavior with respect to sustainable consumption [e.g., 4, 36]. It has been suggested that an inadequate amount of available sustainability information may facilitate such misalignment [37, 38], and that environmental impact information can substantially influence consumption choices [8].

Behavior change interventions have been studied across numerous research domains, such as marketing, health, and information systems [e.g., 39, 40], and scientific contributions have also emerged in the area of sustainable consumption behavior [e.g., 41]. It has been established that positively perceived cueing of commonly conducted sustainability behaviors may lead to an increase of such behavior in the future [42], and experience-driven cueing may be more effective in braking behavioral patterns than plain informative cueing [41, 43].

Promising indications of the potential of technological solutions as drivers of sustainable behavioral change have already been showcased in a multitude of contexts (e.g., smart cities and health and nutrition). However, the underpinnings of such solutions tend to be based on the partially false assumption that imparting information to consumers "causes behavior change, or a change in awareness and attitude that then changes behavior" [33 pp. 367.] Supporting customers' identity and engagement has been suggested as a potentially fruitful path for designing such behavior change interventions [26, 44, 45]. However, investigations into using digital technologies for facilitating sustainable consumption behavior tend to focus on narrow and pre-selected goals. For instance, in the retail context, most investigations 
have focused solely on food waste reduction, product disposal/recycling, or increasing the share of organic produce, and only a few studies have addressed other potential sustainability goals (e.g., locality of produce, reducing meat consumption, food industry ethics, such as fair trade and social equality) [45]. What has remained largely overlooked, is harnessing technology to support the transition toward the customer-centric goals related to sustainable consumption in the retailing industry.

\subsection{Co-creating sustainability value in the retailing industry}

Value co-creation (VCC) in the SDL framework refers to the function of applying resources for the benefit of others [20]. Service, the fundamental unit of exchange in all economies, involves multiple actors collaboratively creating value, i.e., increased wellbeing, subjectively and phenomenologically determined by each beneficiary [46]. Accordingly, companies alone cannot produce and deliver value; rather, they can offer value propositions, which customers may accept [20, 47]. Thus, companies are urged to start focusing on services rather than products (i.e., co-creating value with customers) [48]. Drawing from the SDL framework, we conceptualize use of digital technology in the retail context as service exchange in which two or multiple actors (i.e., the retailer and customers) accept one another's value propositions and integrate possessed resources (e.g., time, consumption data, and algorithms) to co-create value (e.g., environmental sustainability) [20, 21, 46, 49]. However, VCD may also emerge, leading to a decrease in well-being for one of the involved actors [23]. For instance, digital service users may perceive a lack of access to relevant information when they need it or that the resources invested in the process exceed the gained [e.g., 22, 50].

While today's sustainability-related digital services in the retail context tend to rely on types of retrospective feedback on customers' purchases, the extent to which such methods facilitate the co-creation of sustainability value (i.e., improved environmental well-being) is unclear. Regarding omnipresent digital technologies, customer engagement is becoming increasingly focal [51]. Extant literature supports the idea that understanding and helping consumers achieve their sustainability goals and influencing consumption behavior requires active engagement in the servicescape. Aligned with this notion, the SDL framework provides a useful lens for investigating collaborative initiatives and how value propositions are realized in the actual use of the service in question [52]. Furthermore, digital services for co-creating sustainable behavior change regarding food and commodity consumption remains understudied [16]. As the first study to attempt to address these gaps, we investigate how digital services can incite co-creation of sustainability value between the case company and its customers.

\section{Methodology}

We conducted a qualitative case study [27] consisting of 10 in-depth interviews with the case company and its customers. This company operates in a network of regional cooperatives (online and offline), providing food, consumer goods, and services in retail store units from minimarkets to department stores and hypermarkets. It also provides consumers with their personal consumption data on a mobile application, which may be used, for instance, to analyze the carbon footprint of one's grocery shopping or display the origins or nutritional values of purchased items. The open-ended interviews focused on themes generally related to sustainability and digital service provision. The interviews were conducted using a video conferencing tool and lasted 29-102 minutes. They were recorded and transcribed.

The interviews with the company representatives aimed at attaining an understanding on how the case company proposed value to consumers in its region by harnessing digital technologies. Thus, the themes of the case company interviews were related to corporate sustainability goals, sustainability initiatives, customer engagement, and digital services. We opted to interview the case company's regional representatives, who had an in-depth understanding of the company's strategy, mission, and actions toward improving sustainability, as well as its core processes, with particular emphasis on digital services. The representatives interviewed were the vice president of communications and marketing, the chief executive officer, the marketing manager, the director of development, and the senior vice president of retail.

We used an inductive coding procedure [53]. wherein two authors individually coded the data with the SDL lens. The coders assessed the transcribed interviews searching for sustainability-related value propositions, i.e., the company's representations of how value can be created through resource incentives made available for customers with an underlying invitation to a collaborative resource integration process aiming at increasing environmental, social and/or economic wellbeing [20]. The identified value propositions were organized into first-order concepts, second-order themes (groups of value propositions), and third-order aggregated dimensions.

Both coders assessed the transcribed data, teasing out first-order concepts proposed by the company 
respondents for facilitating sustainability value through digital service provision. The concepts were developed from informant-centric terms [53] from instances in which the respondent introduced a corporate initiative for facilitating sustainability, such as involving consumers in developing new store assortment or emphasizing more sustainable products in price tags. For instance, the first-order concept "Supporting local customers' goals by involving them in decision making" was coded for the indication of the opportunity that local customers could suggest sustainable goods and products, such as local bread or plant-based alternatives to be included in the store's assortment. After individually developing the first-order concepts, the two coders compared them and discussed emerging inconsistencies striving for consensus. 16 first-order concepts were finalized.

One of the coding authors grouped similar firstorder concepts into eight second-order themes by looking for similarities and inconsistencies in the categories $[53,54]$. For instance, the first-order concepts "Online store improves availability of locally-sourced products" and "Supporting local actors in value chain and providing local services" were grouped under the second-order theme of "Broad network of online and physical outlets for access to locally-sourced goods and services". Subsequently, another author reviewed the themes and concluded they were coherent and representative of the dataset. Finally, one of the authors developed four dimensions, overreaching the first-order concepts and second-order themes. For instance, the

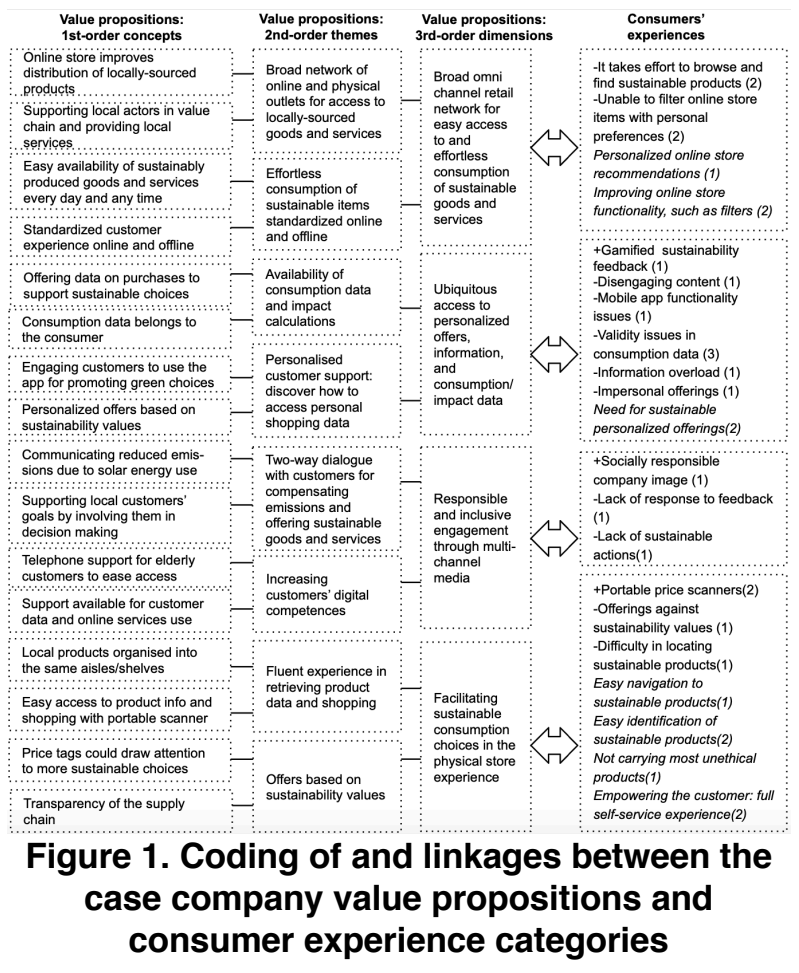

second-order themes "Broad network of online and physical outlets for access to locally-sourced goods and services" and "Effortless consumption of sustainable items standardized online and offline" were aggregated into the third-order dimension of "Broad omni channel retail network for easy access to and effortless consumption of sustainable goods and services." These third-order dimensions represented an aggregated view of the case company's value propositions.

Subsequently, we investigated customers' perceptions of these value propositions. While sustainability value is focal for a growing share of consumers, not all consumers are actively striving to make sustainable choices. To ensure the respondents' internal motivation to the use of sustainable technologies, we opted to interview sustainability- and environmentally aware customers with a high interest in digital services. We distributed a call for respondents on a regional Facebook page devoted to sustainability and technology enthusiasts. To establish relevance and focus, we applied purposeful sampling [55 p. 27] to select five volunteer informants who were frequent customers of the case company and had experience using the case company's digital services. Two male-, two female- and one other-identifying respondents between ages of 28 and 45 were interviewed. The sample included workers, a student, and a stay-at-home parent, each with 3-8 years of experience using the case company's digital services.

The open-ended consumer interviews focused on the themes of personal sustainability values/goals and the positive/negative experiences of using the case company's digital services. To elicit customers' needs and expectations, we asked the informants to consider how the case company could better support their sustainability goals through digital services in the servicescape. This way, we were able to develop potential VCC scenarios. Using thematic data analysis [56], two authors coded the interviews with the lens of the third-order value proposition dimensions (cf. Figure $1)$. The developed codes were further categorized as positive (+) or negative (-) experiences or potential VCC scenarios (italic notations). For instance, two interviewed consumers expressed their preference of personalized offers on the mobile app, and these elicited preferences were coded as "Need for sustainable personalized offerings" and categorized into the dimension of "Ubiquitous access to personalized offers, information, and consumption/ impact data" which was representative of the elicited consumer need. Each of the 32 consumer experiences emerging in the data were categorized in a similar manner. Four positive experiences (indicating potential VCC) and 15 negative experiences (indicating potential VCD) emerged in our analysis. Further, 13 scenarios for potential VCC were 
elicited. The third author reviewed the linkages of the consumer experiences to the value proposition dimensions concluding the analysis was concise and representative of the data.

\section{Findings}

Drawing from our analysis, we propose a preliminary framework for sustainability VCC and VCD through digital services in the retail industry, comprehending four value proposition dimensions and consumer experiences linked therein. Next, we depict each value proposition dimension and their contents.

\subsection{Broad omni channel retail network for easy access to and effortless consumption of sustainable goods and services}

Value propositions. In the interviews with the case company's representatives, locality in goods and products and well-being of local people and organizations were repeatedly mentioned as proposed values. The case company supports local purchasing power by promoting the jobs of local people when possible, and by supporting small firms (i.e., by procuring their services and carrying local produce):

"For example, we made a deal with local fishermen that we would buy the fish they catch from the local lakes. There are many advantages to that. We secure their living and ensure that we always have fish from the lake available while also providing fish recipes for customers and ensuring healthiness through this." (Director of development)

Proposing the value of locality, from the view of the case company, means providing services, such as physical stores (only if possible) or delivery options from online stores, reaching remote locations in Finland, to maintain the vitality of the town. Due to the COVID19 pandemic, the case company launched a telephone service for the elderly, offline customers for placing grocery orders, and arranging deliveries.

The case company's representatives stated that their online store for groceries plays an important role in proposing the values of locality and ethical sustainability. The assortment of the online store includes products from downscale local food suppliers, which can be distributed more widely than when sold only in physical stores. In addition to a broad network of physical outlets, the online store facilitates an effortless experience for customers to purchase such locally produced goods and services. Thus, the main value propositions were related to providing customers with easy and effortless access to sustainable and ethical goods and services: "Wherever the customer is, we can provide a standardized customer experience." (Senior vice president of retail)

Sustainability VCC and VCD. We found four experiences of VCD (e.g., It takes effort to browse and find sustainable products) and elicited three consumer needs (e.g., improving online store functionality, such as filters) linking to "Broad omni channel retail network for easy access to and effortless consumption of sustainable goods and services." While the case company had clear ideas of how to propose easiness and effortlessness to help customers consume more sustainable and locally sourced goods and products, the consumer respondents surprisingly did not report any experiences of VCC in this area. Two of the consumer respondents had used the online store, and both reported few concerns regarding its functionality. One respondent said that the system lacked the possibility of filtering out products that contained animal-based ingredients. To search for products, customers had to remember the exact name of the item they wanted to purchase. Another consumer respondent noted that some plant-based products were categorized falsely as meat or dairy, which made browsing for plant-based alternatives even more difficult. It was noted that one had to be practically an expert in vegan products to find them online or in the physical store, which might, for instance discourage people looking to decrease their meat consumption.

Considering scenarios for using digital services to support sustainability VCC, two consumers would have liked to add a personalization option in the online store to enable specifications of personal preferences as filters. These two consumers both wanted to combine divergent sustainability propositions (e.g., consumption of domestic products and vegan products), which was not currently possible in the online store experience. It was suggested that digital services could automatically remember customers' diets or particular targeted values. As a negative experience, one of the informants explained that they had placed an order for a plant-based item but received an animal product substitute instead, as the original item had been out of stock at the time of collecting the order. Three of the consumer respondents stated that they would have enjoyed being encouraged to try products that matched their values and preferences: "It would be nice if I would get notification 'blimps': there is a new product that I may be interested in based on my choices. And I could buy the item from the local store or order it at home." (Co4)

\subsection{Ubiquitous access to personalized offers, information, and consumption/impact data}

Value propositions. With transparency as one of its key values, the case company opted for collaborative 
and interactive communication with its customers. One of the representatives clarified that a customer's personal consumption data belongs to the customer themself. Hence, the customer should have access to the data, and the right to decide on its use. It can be inferred that the case company supports its customers in following their own choices and values. The case company respondents implied they have a responsibility, shared with its suppliers and producers, of the overall sustainability of their offerings. It was concluded that in the ideal case, both the consumers and the case company agreed that they should share responsibility for sustainability. To foster transparency, the case company provides a mobile application for its customers that presents information about their consumption and its environmental impact. The application includes features such as, offers, consumption data, consumption rate of domestic food, a household carbon footprint calculation, household plastic bag usage, and the nutritional macros of purchased groceries. However, it was emphasized that customers are responsible for their own consumption choices and whether they chose to share their data openly: "We give this information to customers, and customers make their own sustainable choices. They make decisions on their own, but we ensure to the best we can that the information provided to them is as easy as possible to process." (CEO)

In the application, customers could also compare the prices of products between the case company and its competitor. As the application does not support personalization regarding customers' consumption preferences, the informants indicated that there is more potential for promoting sustainable choices than what is currently being offered (i.e., harnessing customer data and the mobile application could enable sustainability related VCC in the future). However, one of the case company representatives emphasized the low adoption rate of the mobile application: ca. $50 \%$ of the company's client base had not adopted the application at all. While accessibility was not regarded an underlying reason for the relatively low rates, it was stated that more customer insight is needed for understanding and tackling the issue.

Sustainability VCC and VCD. Our analysis revealed that only one experience on sustainability VCC and seven VCD experiences were linked to "Ubiquitous access to personalized offers, information and consumption/impact data". Furthermore, four potential VCC scenarios emerged. All the consumer respondents had used the case company's mobile application but mostly for banking and offers. They had all viewed their personal consumption data in the application and found the data interesting, overall. One respondent said that their plastic bag usage data was especially intriguing.
However, the same consumer respondent found the nutrition value calculator disengaging and subjected to information overload.

Four of the consumers were unsatisfied with the offers in the application and found them misaligned with their personal values. Two consumer respondents found it bizarre to receive offers of products, that they did not opt to include in their diet or lifestyle. The information regarding food consumption was also found to be biased, overwhelming, or incorrectly categorized. In fact, plant-based alternatives to animal-based products, such as dairy and meat, were listed under the same categories as substitutive animal products: "The app says that I've bought dairy products for 800 euros within a year... I have bought milk, cream, yoghurts, dairy desserts, cheeses, and yellow butter. But in fact, all my purchases have been vegan." (Co4)

The consumer respondents did not find the available consumption data interesting enough and the use of the application effortless enough to transform their behavior toward more sustainable consumption. Further, four of the consumers reported that they made regular or irregular transactions also with other retailers, which disputed the validity of the household consumption statistics made available in the case company's app. The consumer respondents suggested that the application should use customer data to optimize user experience and support customers' values. This could be achieved, for instance, by providing information and personalized offers that are carefully aligned with customers' preferences.

\subsection{Responsible and inclusive engagement}

Value propositions. The case company's representatives clearly expressed that one of the most important sustainability values for them was proposing support and care for their customers. The case company developed various digital and physical services to help realize this goal, including asking for local customers' opinions and concerns when establishing new retail units in an area. The company actively engaged with consumers through the corporate website, social media channels, and direct email. To foster digital inclusion, the case company had also provided support for its elderly customers with respect to their digital competencies. It claimed to highly value interactive communication with its customers. The vice president of communications and marketing stated that they receive around 7,000 messages per year through the website feedback channel and 10,000-12,000 messages per year through social media and replies to most of the messages.

One of the case company representatives stated that the company acknowledges there is room for 
improvement with respect to the company's sustainability brand. The company had committed to many actions toward lowering its carbon footprint, offering more sustainable alternatives for traditional goods and products, and other incentives. For instance, the company had installed the country's largest solar panel setup on the rooftop of one of its hypermarkets to substantially lower the hypermarket and customers' environmental impact from energy consumption. In addition to using physical in-store signage, various online campaigns, including influencer marketing, website activities and directed social media marketing (Facebook and Instagram) had been undertaken to communicate sustainability-related achievements and propositions to consumers. However, communicating sustainability-related value propositions was found challenging: "How could we communicate more about all the good that we are doing? In my opinion, that is the main point." (Director of development).

Sustainability VCC and VCD. Contradicting with the company representatives' views on their responsible and inclusive engagement with customers, only one VCC experience emerged from the consumer interviews around this value proposition dimension. Further, two VCD experiences (e.g., lack of response to feedback) emerged. At the time of our consumer interviews, the case company's sustainability campaigns were relatively recent, which may have partially explained why there were no signs in the consumers' interviews that the company's sustainability brand communication had taken effect.

The informants found that the case company was mainly known for its affordable products instead of sustainability efforts: "It will not be unnoticed that the local brewery producer $[. .$.$] is carbon neutral [. .$.$] and$ emissions are being calculated in detail... I know these things better than similar things of [the case company]." (Co2.) The informants called for a more responsible and sustainability-driven approach to designing the case company's product range. However, one of the respondents said they were under the impression that the case company does actively aim toward sustainability. The respondents wanted their everyday shopping experience to be fast and easy in contrast to spending time searching for eco-labels, etc. Informants highlighted the importance of visible in-store sustainability labels, such as "The Nordic Swan Ecolabel". Two of the consumer respondents expressed their interest in searching for in-depth information on supply chains at a time convenient to them. One of the respondents said that they would gladly receive communication about sustainability matters, as the only information they are currently receiving is about offers/promotions. Further, one informant had received no response to critical feedback sent via online channels.

\subsection{Facilitating sustainable consumption choices in the physical store experience}

Value propositions. One of the key value propositions of the case company was to ease customers' everyday shopping experience in physical stores by relevant placements and information. For instance, the company offers specific shelves for products that support certain sustainability goals (e.g., local products). The previously mentioned transparency value is relevant also with respect to the transparency of the supply chain. In the future, the case company plans to more transparently provide supply chain data to customers ad-hoc by using blockchain technology. However, this requires commitment from all actors, as transparency might not be complete if one actor in the chain decides not to share information.

Sustainability VCC and VCD. Our analysis found that the dimension "Facilitating sustainable consumption choices in the physical store experience" was linked to two experiences of $\mathrm{VCC}$, two experiences of VCD, as well as seven elicited scenarios of potential sustainability VCC. Portable price scanners are used to add products to customers' shopping baskets while they are walking around the store. One of the consumer respondents suggested using their own mobile devices for scanning and easy retrieval of sustainability-related product details, so that additional devices would not be required. Payment could also be done directly from the customer's account when walking through the checkout, without having to stop at the self-service counter as the current system demands: "You could just walk in, pick up what you need, and then walk away." (Co5)

According to two of the consumer respondents, the products could be organized in a more tailored manner. They suggested that in the future, the physical store could provide a more tailored and digitally assisted shopping path emphasizing the aisles related to the customer's personal preferences, developing digitally assisted recommendations, and using digital labels to support customers' sustainability values. Two of the consumer respondents expressed that they would prefer the case company explicitly remove the most unethical products from the stores: "In a way, I would want the store to make decisions by removing unethical or doubtful products from the assortment. An example would be what I saw in an advertisement from a competitor case company. They had zebra steaks, and the stripes were still visible. I find this harsh. I don't think they should even offer these." (Co3)

\section{Discussion and conclusions}

This study used the SDL lens to investigate the sustainability-related value propositions of a leading 
Finnish case company and related customer experiences when using digital services. We proposed a preliminary framework for sustainability VCC and VCD through digital services in the retail industry with four value proposition dimensions and customer experiences linked therein. Our study provides a threefold theoretical contribution to information systems and service research. First, we adopt a novel approach using the SDL lexicon for combining value propositions of the case company and customer experiences to understand both perspectives as subjective resource integrators in the service exchange potentially leading to $\mathrm{VCC}$ or VCD. The aggregated dimensions of the value propositions offered by the case company were analyzed against consumers responses to these leading to cocreation/destruction of sustainability value, such as social and environmental wellbeing. By doing so, we addressed the call for zooming in on service exchange occurrences using the SDL lens [49]. Our approach differs from that used by other studies that have investigated VCC or VCD from a one-sided perspective [57]. Further, this approach allowed us to obtain an understanding of the phenomenological nature of sustainability VCC/VCD and the experiential nature of value [58].

Second, our findings showcase how providers' value propositions may be poorly perceived by customers. We address calls for further research into the concept of VCD [22, e.g., 23] and find that negative value outcomes may emerge, whereas positive ones are being pursued by the involved stakeholders. Consumers reported obstacles to $\mathrm{VCC}$, particularly in the dimensions of "Ubiquitous access to personalized offers, information, and consumption/impact data" and "Broad omni channel retail network for easy access to and effortless consumption of sustainable goods and services." For instance, consumers reported that products' sustainability information was poorly communicated, while the representatives of the case company discussed that information was actively disseminated to help ease customers' everyday lives. The provider also actively strived to give customers access to their personal consumption data to support their consumption choices, but consumers reported that the mobile application lacked personalization, and was not meeting these expectations. For instance, personally restricted foods were advertised to consumers, which was a VCD source. In line with the SDL thought of phenomenological value [46], our findings hold that to co-create sustainability value customers require relevant information about products based on their personal values and preferences. Accordingly, tailored digital interventions need to be investigated further and fitted to individual consumers' goals and needs as a focal ingredient to facilitating sustainability VCC.
Third, our study is the first to investigate digital consumer services for sustainability VCC in the retail industry. We showcased evidence to support that providing access to consumption data per se is by no means sufficient for co-creating sustainability value [33 pp. 367.] The consumer respondents in our study discussed particularly high motivations toward adopting new technologies for supporting more sustainable consumption and lowering their personal impact on current environmental and social challenges. Interestingly, the corresponding value propositions discussed by the company representatives and corporate website remained for the most part unrealized in the consumer informants' experiences.

The reported study represents a starting point to a broader endeavor of harnessing consumers' personal sustainability goals for digital enabled VCC. From these findings we can already infer that active engagement with customers and smart usage of omnichannel customer data may be the key to designing digital services for mitigating the impact of consumption through VCC. Further, highlighting the VCD potential in digital services for sustainability, our findings indicate that interventions should be designed in the servicescape rather than outside of it. For instance, the value of showcasing carbon footprints seems to decrease if the information is made available only after the shopping experience, and particularly, if the data is not valid and accurate. As the consumer respondents were technologically advanced users, the interviews indicated a strong interest in self-service and use of mobile technologies as source of sustainability VCC in the physical store. Thus, exploration is needed with respect to fruitful value propositions for consumers navigating the aisles of a convenience store. Interesting future research topics reside also in gamified persuasive applications for combining the virtual and physical dimensions of the servicescape with consumers' sustainability goals [cf. 16, 26, 31]. It would also be interesting to investigate how sustainability $\mathrm{VCC}$ and VCD unfold, and drive behavior change with larger samples of consumers and retailers through experimental research design in the servicescape and beyond [59]. One valuable perspective would be to explore the theoretical relations of VCC and VCD as a dynamic, evolving process with two constantly interplaying poles [cf. 60].

This study also has limitations such as the sensitivity of the researchers and the subjective views of the informants. Further, the goal of this study was by no means to develop generalizable claims, and so the small sample size does not yet provide a basis for that. However, there is value in context-produced knowledge obtained by case study methodology [61] such as used here for creating a preliminary framework for 
sustainability VCC. The preliminary framework may be utilized in further research, such as experiments and surveys in the topic area, and to spur further theoretical development and societal impact.

\section{Acknowledgements}

This research has been partly funded by the Foundation for Economic Education, Finland [grant number 34014860].

\section{References}

[1] United Nations: Sustainable consumption and production Goal, https://sustainabledevelopment.un. org/topics/sustainableconsumptionandproduction.

[2] Goodland, R.: Concept of Environmental Sustainability. Annual Review of Ecology and Systematics. 26, 1-24 (1995).

[3] van Loo, E.J., Caputo, V., Nayga, R.M., Verbeke, W.: Consumers' valuation of sustainability labels on meat. Food Policy. 49, 137-150 (2014).

[4] Vermeir, I., Verbeke, W.: Sustainable food consumption: Exploring the consumer "attitude Behavioral intention" gap. Journal of Agricultural and Environmental Ethics. 19, 169-194 (2006).

[5] Davies, A.R.: Co-creating sustainable eating futures: Technology, ICT and citizen-consumer ambivalence. Futures. 62, 181-193 (2014).

[6] Steg, L.: Environmental psychology and sustainable consumption. In: Reisch, L.A. and Thøgersen, J. (eds.) Handbook of Research on Sustainable Consumption. pp. 70-83. Edward Elgar Publishing Limited (2015).

[7] Gardner, G., Assadourian, E., Sarin, R.: The state of consumption today. Routledge (2014).

[8] Shao, J., Ünal, E.: What do consumers value more in green purchasing? Assessing the sustainability practices from demand side of business. Journal of Cleaner Production. 209, 1473-1483 (2019).

[9] Steg, L., Vlek, C.: Encouraging pro-environmental behaviour: An integrative review and research agenda. Journal of Environmental Psychology. 29, 309-317 (2009).

[10] Elliot, S.: Transdisciplinary perspectives on environmental sustainability: A resource base and framework for it-enabled business transformation. MIS Quarterly: Management Information Systems. 35, 197236 (2011).

[11] Xie, K., Wu, Y., Xiao, J., Hu, Q.: Value co-creation between firms and customers: The role of big data-based cooperative assets. Information and Management. 53, 1034-1048 (2016).

[12] Statista: Per capita consumption of meat worldwide 2016-2028,

https://www.statista.com/statistics/1037429/per-capitaconsumption-of-meat-worldwide-by-region/.

[13] Statista: Global plastic waste volume 1950-2050 (in billion metric tons), https://www.statista.com/ statistics/1019774/plastic-waste-volume-globally/.
[14] Statista: Retail \& Trade. https://www.statista.com/ markets/423/retail-trade/

[15] van't Riet, J., Sijtsema, S.J., Dagevos, H., de Bruijn, G.J.: The importance of habits in eating behaviour. An overview and recommendations for future research. Appetite. 57, 585-596 (2011).

[16] Guillen Mandujano, G., Quist, J., Hamari, J.: Gamification of backcasting for sustainability: The development of the gameful backcasting framework (GAMEBACK). Journal of Cleaner Production. 302, 126609 (2021).

[17] Edwards, E.A., Lumsden, J., Rivas, C., Steed, L., Edwards, L.A., Thiyagarajan, A., Sohanpal, R., Caton, H., Griffiths, C.J., Munafò, M.R., Taylor, S., Walton, R.T.: Gamification for health promotion: systematic review of behaviour change techniques in smartphone apps. BMJ open. 6, 1-9 (2016).

[18] Johnson, D., Horton, E., Mulcahy, R., Foth, M.: Gamification and serious games within the domain of domestic energy consumption: A systematic review. Renewable and Sustainable Energy Reviews. 73, 249264 (2017).

[19] Brynjarsdóttir, H., Håkansson, M., Pierce, J., Baumer, E.P.S., DiSalvo, C., Sengers, P.: Sustainably unpersuaded: How persuasion narrows our vision of sustainability. Conference on Human Factors in Computing Systems - Proceedings. 947-956 (2012).

[20] Vargo, S.L., Lusch, R.F.: Evolving to a New Dominant Logic for Marketing. Journal of Marketing. 68, 1-17 (2004).

[21] Vargo, S.L., Koskela-Huotari, K., Vink, J.: The Routledge Handbook of Service Research Insights and Ideas. Routledge, New York (2020).

[22] Lintula, J., Tuunanen, T., Salo, M., Myers, M.D.: When Value Co-Creation Turns to Co-Destruction: Users' Experiences of Augmented Reality Mobile Games. In: Proceedings the 39th International Conference on Information Systems. pp. 1-17. Association for Information Systems (AIS) (2018).

[23] Plé, L., Chumpitaz Cáceres, R.: Not always co creation : introducing interactional co - destruction of value in service - dominant logic. Journal of Services Marketing. 24, 430-437 (2010).

[24] Čaić, M., Odekerken-Schröder, G., Mahr, D.: Service robots: value co-creation and co-destruction in elderly care networks. Journal of Service Management. 29, 178-205 (2018).

[25] Payne, A., Frow, P.: Developing superior value propositions: A strategic marketing imperative. Journal of Service Management. 25, 213-227 (2014).

[26] Spanjaard, D., Freeman, L.: The hidden agenda: emotions in grocery shopping. International Review of Retail, Distribution and Consumer Research. 22, 439457 (2012).

[27] Yin, R.K.: Case Study Research Design and Methods. Sage Publications (2009).

[28] Sheth, J.N., Newman, B.I., Gross, B.L.: Why we buy what we buy: A theory of consumption values. Journal of Business Research. 22, 159-170 (1991).

[29] Holbrook, M.B.: Consumer value: a framework for analysis and research. Routledge, London (1999). 
[30] Vargo, S.L., Akaka, M.A., Vaughan, C.M.: Conceptualizing Value: A Service-ecosystem View. Journal of Creating Value. 3, 117-124 (2017).

[31] Hedin, B., Katzeff, C., Eriksson, E., Pargman, D.: A systematic review of digital behaviour change interventions for more sustainable food consumption. Sustainability. 11, 1-23 (2019).

[32] Klieber, K., Luger-Bazinger, C., Hornung-Prähauser, V., Geser, G., Wieden-Bischof, D., Paraschivoiu, I., Layer-Wagner, T., Möstegl, N., Huemer, F., Rosan, J.: Nudging sustainable behaviour: Data-based nudges for smart city innovations. Nudging sustainable behaviour: Data-based nudges for smart city innovations. In: Proceedings of the ISPIM Innovation Conference Innovating in Times of Crisis. pp. 1-18 (2020).

[33] Huber, M.Z., Hilty, L.M.: Gamification and sustainable consumption: Overcoming the limitations of persuasive technologies. Advances in Intelligent Systems and Computing. 310, 367-385 (2015).

[34] Beckers, S.F., Risselada, H., Verhoef, P.: Customer engagement: A new frontier in customer value management. In: Handbook of service marketing research. pp. 97-120. Edward Elgar Publishing (2014).

[35] Blom, A., Lange, F., Hess, R.L.: Omnichannel-based promotions' effects on purchase behavior and brand image. Journal of Retailing and Consumer Services. 39, 286-295 (2017).

[36] Berger, V., Schrader, U.: Fostering sustainable nutrition behavior through gamification. Sustainability. 8, 1-15 (2016).

[37] Thøgersen, J.: How may consumer policy empower consumers for sustainable lifestyles? Journal of Consumer Policy. 28, 143-177 (2005).

[38] Grunert, K.G., Hieke, S., Wills, J.: Sustainability labels on food products: Consumer motivation, understanding and use. Food Policy. 44, 177-189 (2014).

[39] Fogg, B.J.: Persuasive Technology: Using Computers to Change What We Think and Do. Persuasive Technology: Using Computers to Change What We Think and Do. 1-282 (2003).

[40] Andreasen, A.R.: Social marketing in the 21st century. SAGE Publications (2006).

[41] Midden, C., McCalley, T., Ham, J., Zaalberg Eindhoven, R.: Using persuasive technology to encourage sustainable behavior. Journal of Applied Mechanics-transactions of The Asme. (2008).

[42] Cornelissen, G., Pandelaere, M., Warlop, L., Dewitte, S.: Positive cueing. International Journal of Research in Marketing. 25, 46-55 (2008).

[43] Cozzio, C., Volgger, M., Taplin, R., Woodside, A.G.: Nurturing tourists' ethical food consumption: Testing the persuasive strengths of alternative messages in a natural hotel setting. Journal of Business Research. 117, 268-279 (2020).

[44] Lebel, L., Lorek, S.: Enabling sustainable productionconsumption systems. Annual Review of Environment and Resources. 33, 241-275 (2008).

[45] Meise, J.N., Rudolph, T., Kenning, P., Phillips, D.M.: Feed them facts: Value perceptions and consumer use of sustainability-related product information. Journal of Retailing and Consumer Services. 21, 510-519 (2014).
[46] Vargo, S.L., Lusch, R.F.: Institutions and Axioms: An Extension and Update of Service-Dominant Logic. Journal of the Academy of Marketing Science. 44, 5-23 (2016).

[47] Vargo, S.L., Maglio, P.P., Akaka, M.A.: On value and value co-creation: A service systems and service logic perspective. European Management Journal. 26, 145$152(2008)$.

[48] Vargo, S.L., Lusch, R.F.: It's all B2B...and beyond: Toward a systems perspective of the market. Industrial Marketing Management. 40, 181-187 (2011).

[49] Vargo, S.L., Lusch, R.F.: Service-dominant logic 2025. International Journal of Research in Marketing. 34, 4667 (2017).

[50] Smith, A.: The Value Co-destruction Process: A Customer Resource Perspective. European Journal of Marketing. 47, 1889-1909 (2013).

[51] Williams, K., Chatterjee, S., Rossi, M.: Design of emerging digital services: A taxonomy. European Journal of Information Systems. 17, 505-517 (2008).

[52] Grönroos, C., Voima, P.: Critical service logic: making sense of value creation and co-creation. Journal of the Academy of Marketing Science. 41, 133-150 (2013).

[53] Gioia, D.A., Corley, K.G., Hamilton, A.L.: Seeking Qualitative Rigor in Inductive Research: Notes on the Gioia Methodology. Organizational Research Methods. 16, 15-31 (2013).

[54] Gehman, J., Glaser, V.L., Eisenhardt, K.M., Gioia, D., Langley, A., Corley, K.G.: Finding Theory-Method Fit: A Comparison of Three Qualitative Approaches to Theory Building. Journal of Management Inquiry. 27, 284-300 (2018).

[55] Patton, M.: Qualitative Research \& Evaluation Methods. Sage Publication (2002).

[56] Braun, V., Clarke, V.: Using thematic analysis in psychology. Qualitative Research in Psychology. 3, 77101 (2006).

[57] Baumann, J., le Meunier-Fitzhugh, K., Wilson, H.N.: The challenge of communicating reciprocal value promises: Buyer-seller value proposition disparity in professional services. Industrial Marketing Management. 64, 107-121 (2017).

[58] Jaakkola, E., Helkkula, A., Aarikka-Stenroos, L.: Service experience co-creation: conceptualization, implications, and future research directions. Journal of Service Management. 26, 182-205 (2015).

[59] Tuunanen, T., Kazan, E., Salo, M., Leskelä, R.L., Gupta, S.: From digitalization to cybernization: Delivering value with cybernized services. Scandinavian Journal of Information Systems. 31, 83-96 (2019).

[60] Vartiainen, T., Tuunanen, T.: Value Co-Creation and Co-Destruction in an IS Artifact: Contradictions of Geocaching. In: Proceedings of the 46th Hawaii International Conference on System Sciences. pp. 12661275. IEEE Computer Society, Wailea (2016).

[61] Flyvbjerg, B.: Five Misunderstandings About CaseStudy Research. Qualitative Research Practice. 390-404 (2011). 